\title{
DIRETRIZES CURRICULARES \\ PARA O CURSO DE PEDAGOGIA: TRAJETÓRIA LONGA E INCONCLUSA
}

\author{
LEDA SCHEIBE \\ Centro de Ciências da Educação da Universidade Federal de Santa Catarina \\ Curso de Mestrado da Universidade do Oeste de Santa Catarina - Campus Joaçaba \\ Ischeibe@uol.com.br
}

\section{RESUMO}

Este artigo aborda as discussões e embates acerca da definição das diretrizes curriculares para o Curso de Pedagogia, ocorridos após a aprovação da Lei de Diretrizes e Bases da Educação Nacional de 1996. Focaliza o processo de mobilização e resistência das entidades do campo educacional no sentido de assegurar a docência como base para esse curso e a superação da dicotomia entre licenciatura e bacharelado no seu interior. A análise aponta como cerne do embate a contraposição ao modelo de formação dos Institutos Superiores de Educação e de Cursos Normais Superiores, veiculado pela reforma educacional da década de 1990, o qual se insere em um contexto de políticas neoliberais. Indica ainda que a recente aprovação de diretrizes curriculares para o Curso de Pedagogia (Parecer CNE/CP 5/ 2005 e Resolução CNE/CP //2006) e sua definição como uma licenciatura que forma unificadamente o professor para a educação infantil e anos iniciais do ensino fundamental, constitui uma solução negociada entre as entidades e o Conselho Nacional de Educação. PEDAGOGIA - FORMAÇÃO DE PROFESSORES - EDUCAÇÃO INFANTIL

\section{ABSTRACT}

CURRICULAR GUIDELINES FOR THE PEDAGOGY COURSE: LONGAND UNFINISHED TRAJECTORY. This article addresses the discussions about the definition of curricular guidelines for the Pedagogy Course, as well as the oppositions to them, which occurred after the passage of the National Educational Guidelines and Framework Law of 1996. It focuses the process of mobilization and resistance of the institutions in the educational area in order to ensure teaching as the basis for this course and the overcoming of the dichotomy between teacher certification (licenciatura) and bachelor degree in its interior. The analysis indicates that the central issue is the opposition to the education model of Higher Education Institutes and Higher Basic Education Teacher Education Programs, created by the education reform in the 1990s, which is inserted in a context of neoliberal policies. It also shows that the recent passage of the curricular guidelines for the Pedagogy Course (Official Opinion CNE/CP 5/ 2005 and Resolution CNE/CP / 2006) and its definition as a teacher education program that 
educates the teacher both for the pre-primary school and for the initial grades of primary school, is a solution negotiated between the institutions and the National Council of Education. PEDAGOGY - TEACHER EDUCATION - EARLY CHILDHOOD EDUCATION TEACHER EDUCATION - COLLEGE OFEDUCATION - CURRICULAR GUIDELINES

As diretrizes curriculares para o Curso de Pedagogia, definidas recentemente pela Resolução n. I, de 15 de maio de 2006, do Conselho Nacional de Educação' - CNE - trouxe à tona, mais uma vez, o debate a respeito da identidade do curso e da sua finalidade profissionalizante, agora instituída como licenciatura.

Curso de Pedagogia destina-se, na sua atual formulação legal, à formação de professores para a educação infantil e os anos iniciais do ensino fundamental. Complementarmente, também ao desenvolvimento de competências para o ensino nos cursos de nível médio, na modalidade normal; ao ensino na educação profissional na área de serviços e apoio escolar; às atividades de organização e gestão educacionais; e às atividades de produção e difusão do conhecimento científico-tecnológico do campo educacional.

$\mathrm{Na}$ transição para o novo modelo dos cursos, as instituições de ensino deverão extinguir as habilitações até então em vigor a partir do período letivo seguinte àquele em que for publicada a resolução. $\bigcirc$ projeto pedagógico deve ser protocolado nos sistemas de ensino dentro de um ano e alcançar todos os alunos que iniciarem o curso no próximo período letivo. Em vez das 2.800 horas anteriormente instituídas como mínimo para efetivação do curso, são determinadas agora 3.200 horas de efetivo trabalho acadêmico. Outros itens da regulamentação determinam que pelo menos 2.800 horas devem ser destinadas às aulas, seminários, pesquisas e atividades práticas; as outras 300 horas estarão destinadas ao estágio supervisionado, preferencialmente na docência de educação infantil e anos iniciais do ensino fundamental; e 100 horas, no mínimo, dedicadas a atividades de aprofundamento em áreas específicas de interesse dos alunos.

Essas mudanças curriculares para o Curso de Pedagogia fazem parte de uma ampla, longa e discutida reforma na organização dos cursos de graduação e na formação dos profissionais da educação no Brasil. Após a promulgação da

I. Publicação no DOU n.92, de 16.5.2006, Seção I, p. I I/I2. 
nova Lei de Diretrizes e Bases da Educação Nacional - LDB - em dezembro de 1996, a Secretaria de Ensino Superior do Ministério de Educação - Sesu/ MEC -, por meio do Edital n.4, de 4 de dezembro de 1997, iniciou o processo de mudança curricular solicitando às instituições de ensino superior - IES que enviassem propostas para a elaboração das diretrizes curriculares para os cursos de graduação. De acordo com o Edital:

As Diretrizes Curriculares têm por objetivo servir de referência para as IES na organização de seus programas de formação, permitindo uma flexibilidade na construção dos currículos plenos e privilegiando a indicação de áreas do conhecimento a serem consideradas, ao invés de estabelecer disciplinas e cargas horárias definidas. As Diretrizes Curriculares devem contemplar ainda a denominação de diferentes formações e habilitações para cada área do conhecimento, explicitando os objetivos e demandas existentes na sociedade.

Das orientações gerais contidas no documento é possível depreender os princípios orientadores adotados na reestruturação curricular então iniciada: flexibilidade curricular; dinamicidade do currículo; adaptação às demandas do mercado de trabalho; integração entre graduação e pós-graduação; ênfase na formação geral; definição e desenvolvimento de competências e habilidades gerais. $\bigcirc$ objetivo mais geral, apontado como orientador para a reforma dos cursos de graduação, parece ter sido, fundamentalmente, o de "tornar a estrutura dos cursos de graduação mais flexível” (Catani et al., 200 I , p.74). Para a formação de professores seria possível visualizar nessa flexibilização maior polivalência, de acordo com as demandas do mercado.

No contexto dessas orientações, as Comissões de Especialistas de Ensino - Coesp - institucionalizadas na Sesu/MEC em uma coordenação específica, dedicadas à tarefa de elaborar padrões de qualidade para os cursos de graduação e contribuir para a execução e os procedimentos de avaliação de cursos e instituições de ensino superior, receberam também a incumbência de organizar as diretrizes gerais de currículos para os respectivos cursos, a serem submetidas depois ao CNE, para sua aprovação.

A Comissão de Especialistas de Ensino de Pedagogia - CEEP - recebeu também essa incumbência numa situação particularmente complexa. Cabe situar que o Curso de Pedagogia, na década de 1990, na maior parte das insti- 
tuições, já adotara a atribuição de formar professores para a educação infantil e para os anos iniciais do ensino fundamental, paralelamente ao ordenamento legal que atribuía a este curso, a formação de professores para a Habilitação Específica de Magistério - HEM - e a formação dos especialistas em educação, compreendidos aí os diretores de escola, os orientadores educacionais, supervisores escolares e inspetores de ensino.

A LDB/96, contrariando o que vinha ocorrendo desde 1980 no interior de amplo movimento pela reformulação dos Cursos de Pedagogia e licenciatura, no qual se estabeleceu o princípio da "docência como a base da identidade profissional de todos os profissionais da educação" (Silva, 2003, p.68), determinou a criação dos Institutos Superiores de Educação, ao dispor no artigo 63:

Os Institutos Superiores de Educação manterão:

I - cursos formadores de profissionais para a educação básica, inclusive o curso normal superior, destinado à formação de docentes para a educação infantil e para as primeiras séries do ensino fundamental;

II - programas de formação pedagógica para portadores de diplomas de educação superior que queiram se dedicar à educação básica;

III - programas de educação continuada para os profissionais da educação dos diversos níveis. (Brasil, 1996)

Segundo Saviani (2005, p.24), ao optar-se por atribuir aos Institutos Superiores de Educação a manutenção, além dos cursos normais superiores, de "cursos formadores de profissionais para a educação básica", e não apenas "cursos formadores de professores", essa nova figura institucional transformouse em clara alternativa ao Curso de Pedagogia, "podendo fazer tudo o que estes fazem, porém, de forma mais aligeirada, mais barata, com cursos de curta duração", o que corresponderia ao próprio espírito da LDB, cuja lógica tem "como uma das suas características a diversificação de modelos".

O embate quanto à definição de diretrizes curriculares para o Curso de Pedagogia estava evidente: por um lado, a nova regulamentação trazida pela LDB/96²,

2. Lei Federal 9.493/96, art. 64: A formação de profissionais de educação para administração, planejamento, inspeção, supervisão e orientação educacional para a educação básica será 
descaracterizando o curso e sua finalidade; por outro, a variedade de configurações presentes nos cursos em funcionamento no país.

Não obstante o esforço da Comissão de Especialistas de Ensino de Pedagogia para articular uma proposta com vistas à organização curricular do curso, a definição foi tomada pelo Conselho Nacional de Educação, responsável pela sua regulamentação, somente uma década após a aprovação da LDB/ 96. Nesses anos, estiveram em declarada disputa distintas concepções a respeito da identidade e da organização do curso. À concepção de formação expressa nas reformas instituídas a partir do Governo de Fernando Henrique Cardoso, na esteira das mudanças educacionais neoliberais desenvolvidas na América Latina durante a década de 1990, contrapôs-se o pensamento socialcrítico dos movimentos organizados pelos educadores em busca de uma formulação de políticas públicas de caráter democrático.

\section{TRAJET Ó RIA DAS DIRETRIZES: A PRO POSTA ELABO RADA PELA COMISSÃO DE ESPECIALISTAS/SESU/MEC EM 1999}

A Comissão de Especialistas de Ensino de Pedagogia ${ }^{3}$, composta por educadores vinculados à faculdades de educação de universidades brasileiras elaborou, em maio de 1999, uma proposta de diretrizes curriculares para o curso. Tomou por base para tanto, as sugestões enviadas pelas coordenações de cursos das Instituições de Ensino Superior, em resposta ao solicitado no Edital n. 4/1997, da Sesu/MEC, e também, os resultados de um amplo processo de discussão nacional, em que foram ouvidas as entidades da área, particularmente a Associação Nacional pela Formação dos Profissionais da Educação - Anfope -, apoiada em suas concepções centrais pela Associação Nacional de Pesquisa e Pós-Graduação em Educação - Anped -, o Fórum de Diretores de Faculdades/Centros de Educação das Universidades Públicas Brasileiras - Forumdir -, a Associação Nacional

feita em cursos de graduação em pedagogia ou em nível de pós-graduação, a critério da instituição de ensino, garantida, nesta formação, a base comum nacional.

3. Esta Comissão foi nomeada pela Portaria SESu/MEC n. I 46 de 10 de março de 1998, e composta pelos professores: Celestino Alves da Silva (Universidade Estadual Paulista - Unesp/Marília); Leda Scheibe, presidenta (Universidade Federal de Santa Catarina - UFSC); Márcia Ângela Aguiar (Universidade Federal de Pernambuco - UFPE), Tizuko Morchida Kishimoto (Universidade de São Paulo - USP) e Zélia Mileo Pavão (Pontifícia Universidade Católica - PUC/PR). 
de Administradores Educacionais - Anpae - e o Centro de Estudos Educação e Sociedade - Cedes.

A visão então predominante para a organização do curso foi incorporada na proposta apresentada. Entendeu a Comissão que tal visão não representava simplesmente um senso comum a respeito do tema, mas sim o acúmulo das discussões nacionais que vinham sendo realizadas em amplo processo de mobilização em torno da formação dos educadores que ocorria desde o início da década de 80.

Tal processo de mobilização iniciou-se em 1980 com a criação do Comitê Nacional Pró-Formação do Educador, durante a I a Conferência Brasileira de Educação, realizada na Pontifícia Universidade Católica de São Paulo, no contexto das lutas contra o regime militar pela democratização da sociedade. Sediado em Goiânia, o Comitê tinha o objetivo de mobilizar professores e alunos em torno da reformulação do Curso de Pedagogia, em debate desde 1975 , com os Pareceres 67 e 68/75 e 70 e 7I/76, relatados por Valnir Chagas no Conselho Federal de Educação, que apontavam para um novo sistema de formação de professores ${ }^{4}$. Paradoxalmente, o impulso inicial para a criação do comitê foi dado pelo Ministério de Educação e pelo Conselho Federal de Educação, com o intento de por em discussão os pareceres citados. Em novembro de 1983, no entanto, o Comitê Nacional transformou-se na Comissão Nacional pela Reformulação dos Cursos de Formação dos Educadores CONARCFE -, que deu continuidade à mobilização dos educadores em encontros nacionais, com maior distanciamento dos órgãos oficiais.

Destaque-se que, já neste ano, no I ${ }^{\circ}$ Encontro Nacional da CONARCFE, tomou corpo o conceito de uma "base comum nacional" para a formação dos profissionais da educação no país. Em 1990, no 5 Encontro Nacional da CONARCFE, os educadores presentes decidiram pela criação da Associação Nacional pela Formação dos Profissionais da Educação, a Anfope, que deu continuidade às discussões em novos encontros nacionais, organizando-se também em setores regionais no país (Anfope, 2000).

Nos encontros nacionais, que passaram a ser realizados a partir dessa data sob a coordenação da Anfope, a discussão sobre a base comum nacional

4. Os Documentos Finais dos Encontros Nacionais da Anfope de 92, 94 e 96 recuperam com detalhes esta trajetória. 
para a formação dos profissionais da educação adquiriu relevo, enfatizando-se cada vez mais também a importância de inserir a temática da formação do educador em uma política global, que contemplasse desde a sua formação básica até as condições de trabalho e formação continuada. Da mesma forma, nos encontros e nos documentos dessa associação, foi especialmente destacada a necessidade de superar a dicotomia entre a teoria e a prática, entre o ensino e a pesquisa, entre o conteúdo específico e o conteúdo pedagógico na formação e prática dos educadores, o que deu mais força ao princípio da "docência como base da formação profissional de todos aqueles que se dedicam ao estudo do trabalho pedagógico" (Anfope, 1998, p. 10).

As indicações provenientes das instituições universitárias em atendimento ao Edital n.4 da Sesu/1997 mostraram ampla aceitação desse princípio na formação dos pedagogos. A preparação para a docência na educação infantil e nos anos iniciais do ensino fundamental estava sendo adotada na organização de seus Cursos de Pedagogia e, em muitos casos, como base para a formação das tradicionais habilitações para as quais esses cursos formavam, ou seja, para a formação de profissionais destinados à administração, planejamento, inspeção, supervisão e orientação educacional para a educação básica. Pesou também, para que isso ocorresse, o contexto de descaracterização do modelo de Escola Normal que se iniciara após a aprovação da Lei n. 5.692, de I I de agosto de 197I, conforme indica Saviani (2005), em recente estudo publicado sobre a história da formação docente no Brasil.

A proposta para o Curso de Pedagogia apresentada pela CEEP em maio de 1999, após levantamento realizado junto às instituições de ensino superior do país e às entidades educacionais que discutiam a reformulação dos cursos de formação, contemplou a tendência que já se delineava experimentalmente em muitos cursos. Cabe assinalar, todavia, que os princípios básicos definidos pelo movimento dos educadores e que foram incorporados pela proposta, não se restringiam apenas aos que poderiam estruturar um Curso de Pedagogia, mas serviam como fundamento para outras situações de formação de profissionais da educação.

Ao ser iniciado o processo de discussão das diretrizes curriculares para os cursos de graduação, em 1997, a Comissão de Especialistas de Ensino de Pedagogia envidou esforços na Sesu e no Conselho Nacional de Educação para que fosse levada em conta a discussão nacional a respeito da base comum nacional e, a partir daí, se estabelecessem critérios unificadores para desencadear o de- 
bate sobre as diretrizes específicas para os diversos cursos que formam os profissionais da educação. Essa reivindicação, no entanto, não foi atendida.

A proposta apresentada pela CEEP em 1999 foi encaminhada à administração da Sesu/MEC, mas não chegou a ser apreciada, uma vez que as definições sugeridas entrariam em confronto com a indicação da LDB/96 que em seu artigo 63, ao estabelecer a figura dos Institutos Superiores de Educação, destinou aos Cursos Normais Superiores a "formação de docentes para a educação infantil e para as primeiras séries do ensino fundamental" (Brasil, 1996). Tanto a Sesu quanto a Secretaria de Ensino Fundamental resistiram a enviá-la ao CNE, aguardando a regulamentação do Curso Normal Superior. Mediante mobilização, pelo esforço das entidades, a proposta chegou ao Conselho Nacional acompanhada de um conjunto de assinaturas que solicitava sua apreciação. Mesmo assim, não foi encaminhada para efetiva discussão e deliberação.

Diferentemente do descaso com que foi então recebida no CNE, a proposta foi bem acolhida pela comunidade acadêmica. Silva (2003) apresenta dois motivos para esse acolhimento: o primeiro, por ter adotado os princípios construídos ao longo do movimento dos educadores no que se refere ao Curso de Pedagogia; o segundo, por contemplar tendências em conflito no que diz respeito às funções do Curso de Pedagogia e ao papel do pedagogo.

$\mathrm{Na}$ sua linha argumentativa, a proposta apresenta uma concepção de docência em que as funções do professor se estendem para além do magistério, abrangendo igualmente a gestão e a pesquisa como instrumento de produção e difusão do conhecimento. Com tal entendimento, não faz sentido nesta formação manter a histórica dicotomia entre bacharelado e licenciatura:

curso de Pedagogia porque forma o profissional da educação para atuar no ensino, na organização e gestão de sistemas, unidades e projetos educacionais e na produção e difusão do conhecimento, em diversas áreas da educação é, ao mesmo tempo, uma licenciatura - formação de professores - e um bacharelado - formação de educadores/cientistas da educação. (Anfope, 1998)

Propunha o documento da CEEP que o egresso do Curso de Pedagogia poderia atuar tanto na docência da educação infantil, dos anos iniciais do ensino fundamental, das disciplinas de formação pedagógica do nível médio, quanto 
na organização de sistemas, unidades, projetos e experiências educacionais escolares e não escolares, na produção e difusão do conhecimento científico e tecnológico do campo educacional e nas áreas emergentes do campo educacional (Comissão de Especialistas..., 1999, p.3).

A organização curricular foi definida segundo os princípios: da docência como base da formação, da flexibilização do currículo e da organização dos conteúdos por meio de diversas formas didáticas. A flexibilização curricular emergiu das propostas do movimento dos educadores como uma necessidade, diante da diversidade da realidade educacional brasileira. No documento, aparece como "oferta de componentes curriculares que assegurem possibilidades de aprofundamentos da formação básica e opções diferenciadas de atuação profissional para atender às necessidades e interesses dos alunos" (p.6). Desse modo, o objetivo da flexibilização curricular, na concepção dos educadores, está vinculado aos interesses dos alunos e às demandas sociais. Esses princípios se materializariam em uma estrutura curricular orientada pela idéia de núcleos de estudo, apresentados como alternativa aos currículos mínimos.

Organizada em três grandes núcleos, a estrutura curricular ficaria assim delineada:

I. Conteúdos básicos: articuladores da relação teoria e prática, referentes aos contextos

a. histórico e sociocultural, compreendendo os fundamentos filosóficos, históricos, políticos, econômicos, sociológicos, psicológicos e antropológicos;

b. da educação básica, compreendendo estudos dos conteúdos curriculares da educação básica, os conhecimentos didáticos, o estudo dos processos de organização do trabalho pedagógico e o estudo das relações entre educação e trabalho;

c. do exercício profissional em âmbitos escolares e não-escolares, articulando saber acadêmico, pesquisa e prática educativa.

2. Estudos de aprofundamento elou diversificação da formação: referem-se "à diversificação da formação do pedagogo [que] é desejável para atender às diferentes demandas sociais e para articular a formação aos aspectos inovadores que se apresentam no mundo contemporâneo" (Comissão de Especialistas, 1999, p.3). Propõe ainda o apro- 
fundamento de conteúdos da educação básica ou o oferecimento de conteúdos voltados às áreas de atuação profissional priorizadas nos projetos das IES.

3. Estudos independentes: realizados mediante monitorias e estágios, programas de iniciação científica, estudos complementares, cursos em áreas afins, integração com cursos seqüenciais correlatos à área, participação em eventos científicos do campo da educação, entre outros.

A flexibilização poderia ocorrer, segundo a proposta, pelo menos em dois âmbitos. No que se refere a diferenças curriculares interinstitucionais, tratarse-ia da possibilidade institucional de dar ao curso uma configuração particular, sem ferir a sua característica universal, de acordo com as condições objetivas relativas ao seu corpo docente, estrutura física, objetivos da formação, entre outros. No que se refere à integralização curricular individual do acadêmico, os núcleos relativos aos tópicos de estudos de aprofundamento e/ou diversificação da formação, e aos estudos independentes, confeririam a possibilidade de trajetórias formativas singulares.

A carga horária mínima para realização do curso seria de 3.200 horas, sendo 2.560 destinadas a atividades didáticas obrigatórias, laboratórios e práticas pedagógicas e 640 horas distribuídas entre os estudos independentes e o trabalho de conclusão de curso. As 640 horas, pela flexibilização intracurricular, possibilitariam aos acadêmicos desenvolver estudos diferenciados em uma mesma fase/curso/período.

As práticas pedagógicas abrangeriam três modalidades consideradas como instrumentos de: integração e de conhecimento do aluno perante à realidade do seu campo profissional, a ser desenvolvido ao longo do curso; iniciação à pesquisa e ao ensino; iniciação profissional, em estágio supervisionado. As diferentes modalidades podem ser concomitantes, tornando-se mais complexas e se verticalizando de acordo com o desenvolvimento das atividades durante o curso.

Após 1999, outros documentos foram encaminhados ao Conselho Nacional de Educação reafirmando o conteúdo da proposta elaborada pela Comissão de Especialistas. Cabe destacar o "Posicionamento Conjunto das Entidades" (Boletim da Anfope, 200 I), entregue ao CNE em novembro de 200 I, 
subscrito pelas seguintes entidades: Anped, Anfope, Anpae, Forumdir, Cedes e Fórum Nacional de Defesa da Formação de Professores. Neste documento, ao serem reafirmadas as diretrizes apresentadas pela CEEP em 1999, deu-se especial ênfase a duas teses defendidas pelo movimento: "A base do Curso de Pedagogia é a docência" (p. I4); e "O Curso de Pedagogia, porque forma o profissional de educação para atuar no ensino, na organização e gestão de sistemas, unidades e projetos educacionais e na produção e difusão do conhecimento, em diversas áreas da educação, é, ao mesmo tempo, uma Licenciatura e um Bacharelado" (p. 15).

No período de maio de 1999 a abril de 2005, no que se refere às diretrizes para o Curso de Pedagogia, constata-se um grande e significativo silêncio tanto por parte do Ministério de Educação quanto do Conselho Nacional de Educação. Questões concernentes à regulamentação do curso só apareceram transversalmente no bojo das normatizações do Curso Normal Superior e das Diretrizes Curriculares Nacionais para a Formação de Professores em Nível Superior, Cursos de Licenciatura de Graduação Plena. Educadores e entidades acompanharam o movimento da legislação, mobilizando-se sempre para que, mesmo indiretamente, o Curso de Pedagogia estivesse na pauta das políticas de formação de professores.

\section{CURSO DE PEDAGO GIA VERSUS CURSO NORMAL SUPERIOR}

Após vários anos de expectativa, sob fortes pressões das comunidades acadêmica e educacional-empresarial, o Conselho Nacional de Educação divulgou, no dia 17 de março de 2005, para apreciação da sociedade civil, uma minuta de Resolução das Diretrizes Curriculares Nacionais para os cursos de graduação em Pedagogia. $\bigcirc$ documento foi amplamente rejeitado pela comunidade acadêmica, por encaminhar, para o curso de Pedagogia, diretrizes claramente identificadas com o Curso Normal Superior.

A minuta de resolução apresentou diretrizes definindo o Curso de Pedagogia como licenciatura, com duas habilitações distintas: magistério da educação infantil; e magistério dos anos iniciais do ensino fundamental, nos seguintes termos: "o projeto pedagógico de cada instituição poderá prever qualquer uma das habilitações ou ambas, na forma de estudos concomitantes ou subseqüentes" (Brasil, 2005), assim como estabelecido para o Curso Normal Supe- 
rior. Abriu a possibilidade ao estudante de realizar as duas habilitações, mas de forma desintegrada.

Quando a minuta de resolução foi divulgada, houve nova mobilização de educadores, especialmente mediante a lista de discussão da Anfope ${ }^{5}$. Tais manifestações foram sintetizadas em documento assinado pela Anfope, Anped e Cedes e enviado ao Conselho Nacional de Educação com solicitação de uma audiência pública antes da aprovação definitiva das diretrizes.

As principais críticas apontadas no documento, com relação à minuta de resolução, divulgada em março de 2005, são as seguintes:

- Contraria as aspirações históricas dos educadores em relação às diretrizes curriculares nacionais para o Curso de Pedagogia.

- Reduz o Curso de Pedagogia ao que se pretendeu estabelecer para os Cursos Normais Superiores. O projeto do CNE não leva em consideração o fato de que é o Curso de Pedagogia o espaço acadêmico de que a universidade brasileira dispõe para os estudos sistemáticos e avançados da área da educação. As competências indicadas no artigo $3^{\circ}$ explicitam a concepção instrumental da formação de professores para a educação infantil e séries iniciais do ensino fundamental, desconsiderando as contribuições presentes nos documentos de diretrizes elaborados pelas entidades.

- A proposição de um bacharelado pós-licenciatura, com a duração de 800 horas, apostilado ao diploma, "visando ao adensamento em formação científica”, representa clara desvalorização da formação para a docência, cuja capacitação, alijada "do adensamento teórico", da pes-

5. Circularam na lista de discussão documentos provenientes de diversas universidades, associações, encontros e reuniões de diversas partes do país: Universidade Federal do Piauí/Centro de Ciências da Educação; Universidade de Brasília/Faculdade de Educação; Universidade Estadual de Campinas/Faculdade de Educação; Universidade Estadual do Oeste do Paraná/ Curso de Pedagogia, documento síntese do encontro das instituições formadoras dos profissionais de Pedagogia do Estado do Paraná; Universidades da Paraíba (Federal da Paraíba, Federal de Campina Grande, Estadual da Paraíba) documento conjunto dos coordenadores dos cursos de Pedagogia; Universidade de São Paulo/ Faculdade de Educação; Associação de Escolas Superiores de Formação de Profissionais do Ensino (RS); Universidade Federal de Roraima/ Centro de Educação; Centro de Estudos Educação e Sociedade; Documento dos representantes da Anfope no Estado de Santa Catarina; Universidade Católica de Goiás; Universidade Federal de Pernambuco/ Centro de Educação. 
quisa e da produção de conhecimento, que deveria ser sua base, reduz-se, então, ao pragmatismo da docência para as séries iniciais da educação fundamental ou para a educação infantil, aprofundando a dicotomia entre teoria e prática.

- Tal formulação desconsiderou a particularidade da Pedagogia como uma das "ciências práticas" mais ricas em tradição (Schmied-Kowarzik), o que lhe daria a condição de formar o bacharel e o licenciado ao mesmo tempo, sem dicotomias, como prevêem as propostas de diretrizes curriculares elaboradas pelas duas últimas Comissões de Especialistas do Curso de Pedagogia da Sesu/MEC e referendadas pelas entidades representativas dos educadores.

- Existe grande dissonância entre a concepção de organização curricular do Curso de Pedagogia expressa no projeto de resolução e o desenho do projeto pedagógico e curricular contido na proposta de diretrizes curriculares elaborada pela Comissão de Especialistas da Educação da Sesu.

- Ao definir a formação de especialistas nas áreas previstas no artigo 64 da LDB, a proposta de resolução o faz de maneira imprecisa, invocando as exigências do artigo 67 da mesma lei para estabelecer que essa formação será feita exclusivamente para licenciados, podendo levar à compreensão de que a mesma se dê apenas na pós-graduação, o que fragmentaria a formação e contribuiria com a abertura de um novo e atraente nicho de mercado para os cursos de especialização, quase todos, hoje, nas mãos das IES privadas, o que significaria a privatização e a elitização da formação desses profissionais, em cursos de duvidosa qualidade, acessíveis apenas aos formandos em condições econômicas de dar continuidade à sua profissionalização.

processo de mobilização nacional, desencadeado em prol de diretrizes que contemplassem as propostas construídas historicamente pelo movimento dos educadores, surtiu algum efeito. A partir dele, uma comissão do CNE elaborou novo parecer sobre as diretrizes curriculares nacionais para o Curso de Pedagogia, aprovado em reunião do Conselho Pleno do Conselho Nacional de Educação em 13 de dezembro de 2005, com a presença de representantes da Anfope, Cedes e Forumdir. Após a reunião, em e-mail encaminhado à lista de discussão da Anfope, a professora Iria Brzezinski, que re- 
presentou o Cedes na ocasião, parafraseando Anísio Teixeira, ponderou significativamente: "Vitória? Porém meia vitória".

parecer foi estruturado em três partes: relatório, voto da comissão e decisão do Conselho Pleno. O relatório se compõe de uma introdução na qual explicita a trajetória da construção das diretrizes curriculares nacionais para o Curso de Pedagogia e faz um breve histórico do curso desde a sua criação em 1939. Em seguida, contempla a finalidade, princípios, objetivos, perfil do licenciado, organização do curso, duração dos estudos e implantação das diretrizes.

Diferentemente do que fora apontado na minuta de resolução de março de 2005, esse parecer ampliou a formação do pedagogo no sentido de contemplar "integradamente à docência, a participação da gestão e avaliação de sistemas e instituições de ensino em geral, a elaboração, a execução, o acompanhamento de programas e atividades educativas" (Brasil, 2005, p.6).

As funções estabelecidas para os formados em Pedagogia aproximamse daquelas reivindicadas pelo movimento dos educadores, pois sinalizam para um avanço no que se refere à superação da dicotomia entre licenciatura e bacharelado. Ao menos em tese, indica que a formação no Curso de Pedagogia é mais abrangente que aquela oferecida no Curso Normal Superior:

curso de Licenciatura em Pedagogia destina-se à formação de professores para exercer funções de magistério na Educação Infantil e nos anos iniciais do Ensino Fundamental, nos cursos de Ensino Médio, na modalidade Normal, de Educação Profissional na área de serviços e apoio escolar e em outras áreas nas quais sejam previstos conhecimentos pedagógicos. As atividades docentes também compreendem participação na organização e gestão de sistemas e instituições de ensino, englobando: -planejamento, execução, coordenação, acompanhamento e avaliação de tarefas próprias do setor da Educação; - planejamento, execução, coordenação, acompanhamento e avaliação de projetos e experiências educativas não-escolares; - produção e difusão do conhecimento científicotecnológico do campo educacional, em contextos escolares e não-escolares. (Brasil, 2005, p.7-8)

Na organização curricular, retoma-se a idéia de "núcleos de estudos" elaborada pela Comissão de Especialistas em 1999: 
A organização curricular do curso de Pedagogia oferecerá um núcleo de estudos básicos, um de aprofundamento e diversificação de estudos e outro de estudos integradores que propiciem, ao mesmo tempo, amplitude e identidade institucional, relativas à formação do licenciado. Compreenderá, além das aulas e dos estudos individuais e coletivos, práticas de trabalho pedagógico, as de monitoria, as de estágio curricular, as de pesquisa, as de extensão, as de participação em eventos e em outras atividades acadêmico-científicas, que alarguem as experiências dos estudantes e consolidem a sua formação. (Brasil, 2005, p. I I)

Em relação à proposta da Comissão de Especialistas observa-se uma especial diferenciação na denominação do último núcleo. Fazem parte desse núcleo, "estudos integradores", as atividades de extensão, como já previa a minuta de resolução. Em documento encaminhado às entidades do setor da educação, em maio de 2005, o Sindicato Nacional dos Docentes das Instituições de Ensino Superior - Andes, demonstrou preocupação com a introdução dessas atividades no currículo:

... a partir daí, os estudantes são incluídos em projetos comunitários compondo carga curricular, obrigatórios para as instituições e sendo observados na situação de avaliação institucional. Essas atividades práticas encontram um campo fértil de articulação com a legislação promulgada no governo FHC que trata do serviço voluntário, a ser normatizado por cada IES6. (Andes, 2005, p.6-7)

Outro aspecto importante na organização curricular diz respeito à duração do curso, que estabelece um mínimo de 3.200 horas, diferenciando-se do mínimo de 2.800 horas previsto nas diretrizes curriculares nacionais para a formação de professores em nível superior, cursos de licenciatura de graduação plena7. A duração dos estudos e divisão do tempo referente às 3.200 horas ficou com a seguinte configuração: 2.800 horas dedicadas às atividades formativas como assistência às aulas, realização de seminários, participação e

6. Legislação Federal n. 9.608, de 18 de fevereiro de 1998, Lei Complementar n. 180 de 16 de julho de 1999.

7. Conforme CNE/CP Resolução n. I/2002 e CNE/CP Resolução n. 2/2002. 
realização de pesquisas, consultas a bibliotecas e centros de documentação, visitas a instituições educacionais e culturais, atividades práticas, participação em grupos cooperativos de estudos; 300 horas dedicadas ao estágio supervisionado prioritariamente em educação infantil e anos iniciais do ensino fundamental, contemplando também outras áreas específicas, se for o caso, conforme projeto pedagógico da instituição; 100 horas de atividades teórico-práticas de aprofundamento em áreas do interesse dos alunos, por meio da iniciação científica, da extensão e da monitoria (Brasil, 2005, p. 15).

As habilitações foram extintas. $\bigcirc$ Curso de Pedagogia - licenciatura deverá formar integradamente para o conjunto das funções a ele atribuídas. $\bigcirc$ Parecer CNE/CP 5/2005 sugere que cada instituição, no projeto pedagógico do curso, circunscreva áreas ou modalidades de ensino que proporcionem aprofundamento do estudos. Sugere como possibilidades

....a educação a distância, educação de pessoas com necessidades educacionais especiais, educação de pessoas jovens e adultas, educação étnico-racial, educação indígena, educação nos remanescentes de quilombos, educação do campo, educação hospitalar, educação prisional, educação comunitária ou popular. (Brasil, 2005, p 10)

A comprovação do aprofundamento em uma das áreas constará do histórico escolar do egresso.

A proposta da Comissão de Especialistas definia a estrutura curricular geral fundada em três princípios - docência como base comum da formação, flexibilização do currículo e organização de conteúdos por meio de diversas formas didáticas. Já o Parecer do CNE determina uma configuração diferenciada. Sob a justificativa de que o curso trabalhará com um repertório de informações e habilidades composto por pluralidade de conhecimentos, fundamenta-se nos princípios da interdisciplinaridade, contextualização, democratização, pertinência e relevância social, ética e sensibilidade afetiva e estética. São princípios mais abrangentes, que permitem todo e qualquer tipo de configuração curricular, dependendo dos interesses teórico-práticos de cada instituição.

A integralização dos estudos dar-se-á mediante disciplinas, seminários e atividades de natureza predominantemente teórica; práticas de docência e gestão educacional; atividades complementares - envolvendo o planejamento 
e o desenvolvimento progressivo do trabalho de curso; e, ainda, estágio curricular.

Significativamente, o parecer não se refere à formação do pedagogo, mas à formação do licenciado em pedagogia.

\section{CONSIDERAÇÕES FIN AIS}

No cerne das discussões que problematizaram a definição das diretrizes específicas para o Curso de Pedagogia, encontra-se a resistência do movimento dos educadores à proposta do modelo de formação instituído pela reforma educacional dos anos 1990. Com base no esforço pela superação de uma organização educacional inserida predominantemente no contexto das políticas neoliberais, as entidades educacionais já apontadas contrapuseram à racionalidade técnica e à inclusão de natureza sobretudo formal das políticas públicas em construção, princípios para um desenvolvimento crítico e social. A reivindicação de uma base comum de formação para todos os profissionais da educação afirmou-se como bandeira para a organização de um sistema unificado nesta área de profissionalização, reconhecidamente estratégica no âmbito da regulação social.

Dois grandes princípios de natureza epistemológica foram considerados fundamentais ou representativos para o desenvolvimento de uma formação adequada na direção apontada: a docência como base ${ }^{8}$ dessa formação; e a unidade da licenciatura e do bacharelado nos Cursos de Pedagogia.

A docência como base, tanto da formação quanto da identidade dos profissionais da educação, insere-se na sua compreensão como ato educativo intencional voltado para o trabalho pedagógico escolar ou não-escolar. A prática docente, portanto, é assumida como eixo central da profissionalização no campo educacional, mobilizadora da teoria pedagógica.

A unidade entre licenciatura e bacharelado nos cursos de Pedagogia relaciona-se diretamente com a idéia da docência como fulcro do processo for-

8. O princípio da docência como base foi definido no Encontro Nacional para a Reformulação dos Cursos de Preparação de Recursos Humanos para a Educação, promovido pela Sesu/ MEC, em Belo Horizonte (MG), em novembro de 1983. 
mativo dos profissionais da educação, dando suporte conceitual e metodológico para a união entre teoria e prática.

Apoiada no Parecer CNE 5/2005, aprovado em 13 de dezembro de 2005, a resolução que agora institui as diretrizes curriculares nacionais para o Curso de Pedagogia, apresenta-se como uma solução, mesmo que provisória, para uma controvérsia que se estende há pelo menos 25 anos. O CNE decidiu-se por uma posição negociada, ao apropriar-se de aspectos da proposta já delineada pela Comissão de Especialistas de Ensino de Pedagogia em 1999, mas sem abrir mão da definição do curso apenas como licenciatura. Há ambigüidades na sua formulação, em razão das determinações anteriores, constantes tanto do que instituiu a LDB/1996, como das outras normatizações que conceberam de modo dicotomizado a formação dos profissionais da educação.

O resultado das negociações consiste na definição do Curso de Pedagogia como uma licenciatura para a docência polivalente, requerida para a educação/escolarização de zero a dez anos, diferentemente do que foi definido para os Cursos Normais Superiores, cuja formação abrange duas habilitações: uma para a educação infantil e outra para os anos iniciais do ensino fundamental. A formulação aprovada prevê, pelo menos no interior da formação para o atendimento às crianças de zero a dez anos, e da docência que implica os processos de alfabetização nas diversas áreas do conhecimento, uma base comum: a formação integrada do professor para educação infantil e anos iniciais do ensino fundamental. Esta é também a base necessária às outras funções a que se propõe o curso.

A prática da docência como base, segundo Kuenzer e Rodrigues (2006), corre o risco de ser "uma expressão da epistemologia da prática". Decorre daí o grande desafio que precisa ser enfrentado para que esta prática venha a se constituir, nos projetos pedagógicos de curso, no princípio educativo gramsciano: o desafio é estabelecer uma formação teórica sólida, com base no conhecimento científico e na pesquisa consolidada, e não ceder à incorporação da racionalidade técnica ou do praticismo pedagógico predominante na epistemologia da reforma educacional oficial, na qual se vincula o conhecimento formativo a uma prática imediatista.

Muitas questões, evidentemente, permanecem. A resolução deixa interrogações que precisam ser discutidas pela comunidade educacional. Qual é efetivamente o grau de autonomia e flexibilização que os projetos político- 
pedagógicos têm em relação à constituição dos cursos? Que critérios serão necessários que para assegurar a certificação dos trabalhos possíveis de serem realizados pelo licenciado em Pedagogia? Quanto ao estágio supervisionado (mínimo de 300 horas), haverá determinações mais específicas, que depois serão cobradas pelos indicadores de avaliação dos cursos? Sem falar no desafio contido também na definição dos componentes de conteúdos necessários para abranger a formação proposta.

\section{REFERÊN CIAS BIBLIO GRÁFICAS}

ASSOCIAÇÃO NACIONAL DE DOCENTES DO ENSINO SUPERIOR - Andes. Sindicato Nacional. Agenda para a educação superior. uma proposta do Andes - SN para o Brasil de hoje. In: CONGRESSO DO ANDES - SN, 24. Braślia: TechnoArte, 2005.

ASSOCIAÇÃO NACIONAL PELA FORMAÇÃO DOS PROFISSIONAIS DA EDUCAÇÃO Anfope. Documento Final do $9^{\circ}$ Encontro Nacional. Brasilia, 1998.

Documento Final do $10^{\circ}$ Encontro Nacional. Brasília, 2000.

ASSOCIAÇÃO NACIONAL PELA FORMAÇÃO DOS PROFISSIONAIS DE EDUCAÇÃO (Anfope) et al. Documento conjunto. In: SEMINÁRIO NACIONAL SOBRE A FORMAÇÃO DOS PROFISSIONAIS DA EDUCAÇÃO, 7. Brasilia, 2005. mimeo.

BOLETIM DA ANFOPE. V. 7, n. I5, dez. 2001.

BRASIL. Lei n.9.394/96, de 20.12.1996. Estabelece as diretrizes e bases para a educação nacional. Diário Oficial da União. Brasília: Gráfica do Senado, v. 134, n. I.248, p.27.83327.84I, 23 dez. 1996.

BRASIL. Conselho Nacional de Educação. Parecer CNE/CP 5, 13. 12.2005. Brasília, 2005. Resolução n. I, 15.5.2006. Diário Oficial da União, n.92, seção I, p. I I12, 16 maio 2006.

Minuta de resolução de diretrizes curriculares da pedagogia divulgada pelo Conselho Nacional de Educação. Brasilia, 17 mar. 2005.

BRZEZINSKI, I. Participação Reunião CNE. Relatório Brzezinski. [mensagem pessoal] Mensagem recebida por: anfope@uol.com.br; em: 24 fev. 2006.

CATANI, A. M. et al. Políticas públicas da educação superior. In: MOROSINI, M. (org.). Educação superior em periódicos nacionais. Brasília: MEC, Inep, Comped, 200 I p.7 I - 102 
COMISSÃO DE ESPECIALISTAS DE ENSINO DE PEDAGOGIA. Proposta de diretrizes curriculares para o curso de pedagogia. Brasília: MEC, Sesu, 1999. mimeo.

KUENZER, A. Z; RODRIGUES, M. de F. As Diretrizes curriculares para o curso de pedagogia: uma expressão da epistemologia da prática. In: XIII ENDIPE, 2006, Recife-PE. Recife: Bagaço, 2006. p. 185-12.

SAVIANI, D. História da formação docente no Brasil: três momentos decisivos. Revista do Centro de Educação, Santa Maria, v.30, n.2, p. I I-26, 2005.

SILVA, C. S. B. Curso de pedagogia no Brasil: história e identidade. 2.ed. rev. e ampl. Campinas: Autores Associados, 2003.

Recebido em: setembro 2006

Aprovado para publicação em: outubro 2006 